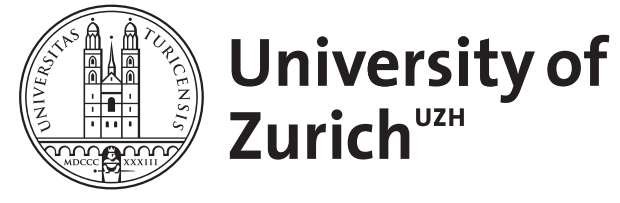
Archive

University of Zurich

University Library

Strickhofstrasse 39

CH-8057 Zurich

www.zora.uzh.ch

Year: 2012

\title{
Hypoxia in the eye: a two-sided coin
}

Grimm, C ; Willmann, G

DOI: https://doi.org/10.1089/ham.2012.1031

Posted at the Zurich Open Repository and Archive, University of Zurich

ZORA URL: https://doi.org/10.5167/uzh-64895

Journal Article

Originally published at:

Grimm, C; Willmann, G (2012). Hypoxia in the eye: a two-sided coin. High Altitude Medicine and Biology, 13(3):169-175.

DOI: https://doi.org/10.1089/ham.2012.1031 


\title{
Hypoxia in the Eye: A Two-Sided Coin
}

\author{
Christian Grimm ${ }^{1}$ and Gabriel Willmann²
}

\begin{abstract}
Grimm, Christian, Gabriel Willman. Hypoxia in the eye: A two-sided coin. High Alt Med Biol. 13:169-175, 2012.— Tissue oxygenation in general and hypoxia in particular are important regulators of retinal physiology and pathophysiology. Reduced oxygen tension and hypoxia-inducible transcription factors along with some of their target genes are critically involved in retinal development, and especially in the generation of a normal retinal vasculature. Well-timed hypoxia is thus vital for the young eye to establish proper retinal function and vision. However, when hypoxia is ill-timed, reduced oxygen tension may be associated with the development of retinal pathologies, including retinopathy of prematurity, diabetic retinopathy, glaucoma, age-related macular degeneration, or high altitude retinopathy. Here, reduced oxygen tension activates a hypoxic response that culminates in an increased expression of vascular endothelial growth factor. This causes pathological neovascularization of the delicate neuronal retina, a process that may ultimately lead to loss of vision. In contrast, preconditioning by welldefined and controlled short-term hypoxia is not devastating for the retina but instead induces a molecular response that provides protection to neuronal cells. Detailed investigation of hypoxic mechanisms during development and adulthood may thus reveal factors, which may be targeted by therapeutic approaches to save and preserve vision in patients.
\end{abstract}

Key Words: hypoxia inducible factor, erythropoietin, ophthalmic changes

\section{Introduction}

V ISIBLE LIGHT HAS TO REACH the light-sensitive photoreceptors in the retina efficiently and with minimal scattering to ensure maximal sensitivity and visual acuity. Thus, cornea, lens, and vitreous are clear and avascular structures that allow maximal penetrance for those wavelengths of light useful to the visual system. Although these structures do not contain blood vessels in the adult eye, oxygen is nevertheless an important regulator of their physiology. Insufficient oxygenation of the cornea, for example, has been associated with pathological vascularization influencing tissue integrity and visual acuity (Safvati et al., 2009). Increased oxygenation of the lens, on the other hand, may reduce lens clarity and thus sensitivity of the visual system (McNulty et al., 2004). Although control of oxygenation in these tissues is of high importance for the process of vision, this review will focus on the significance of fine-tuned oxygen levels for the retina during development and in the adult eye. Disturbed oxygenation is associated with the pathology of several blinding diseases of the retina (Fig. 1A-1D), and may also impact on retinal function and tissue integrity at high altitudes.

\section{Hypoxia in Retinal Pathologies: The Bad Side of the Coin}

\section{High altitude-associated changes}

Reduced oxygen levels at high altitude correlate with several retinal changes in human subjects. Studies in mountaineers revealed that an ascent to high altitude may cause morphological and functional changes of the retina, such as optic disc swelling, changes of macular function including color discrimination, altered retinal and choroidal blood flow, and retinal hemorrhages (Frayser et al., 1970; Wiedman, 1975; Pavlidis et al., 2005; Morris et al., 2007; Bosch et al., 2008, 2009; Willmann et al., 2010, 2011; Ho et al., 2011; Fischer et al., 2012). While some of these changes present physiological adaptive mechanisms to high altitude exposure such as increased blood flow and increased tortuosity of blood vessels, others present potentially pathological changes to hypoxia, such as optic disc swelling or retinal hemorrhages. Interestingly, a significant portion of high altitude mountaineers develop detectable retinal hemorrhages only after their return to base camp from very high altitudes (Barthelmes et al., 2011). However, most of the observed changes are reversible with time, suggesting that

\footnotetext{
${ }^{1}$ Laboratory for Retinal Cell Biology, Department of Ophthalmology, Zurich Centre for Integrative Human Physiology (ZIHP), and Neuroscience Centre (ZNZ), University of Zurich, Zurich, Switzerland.

${ }^{2}$ University Eye Hospital and Institute for Ophthalmic Research, Centre for Ophthalmology University of Tübingen, Germany.
} 

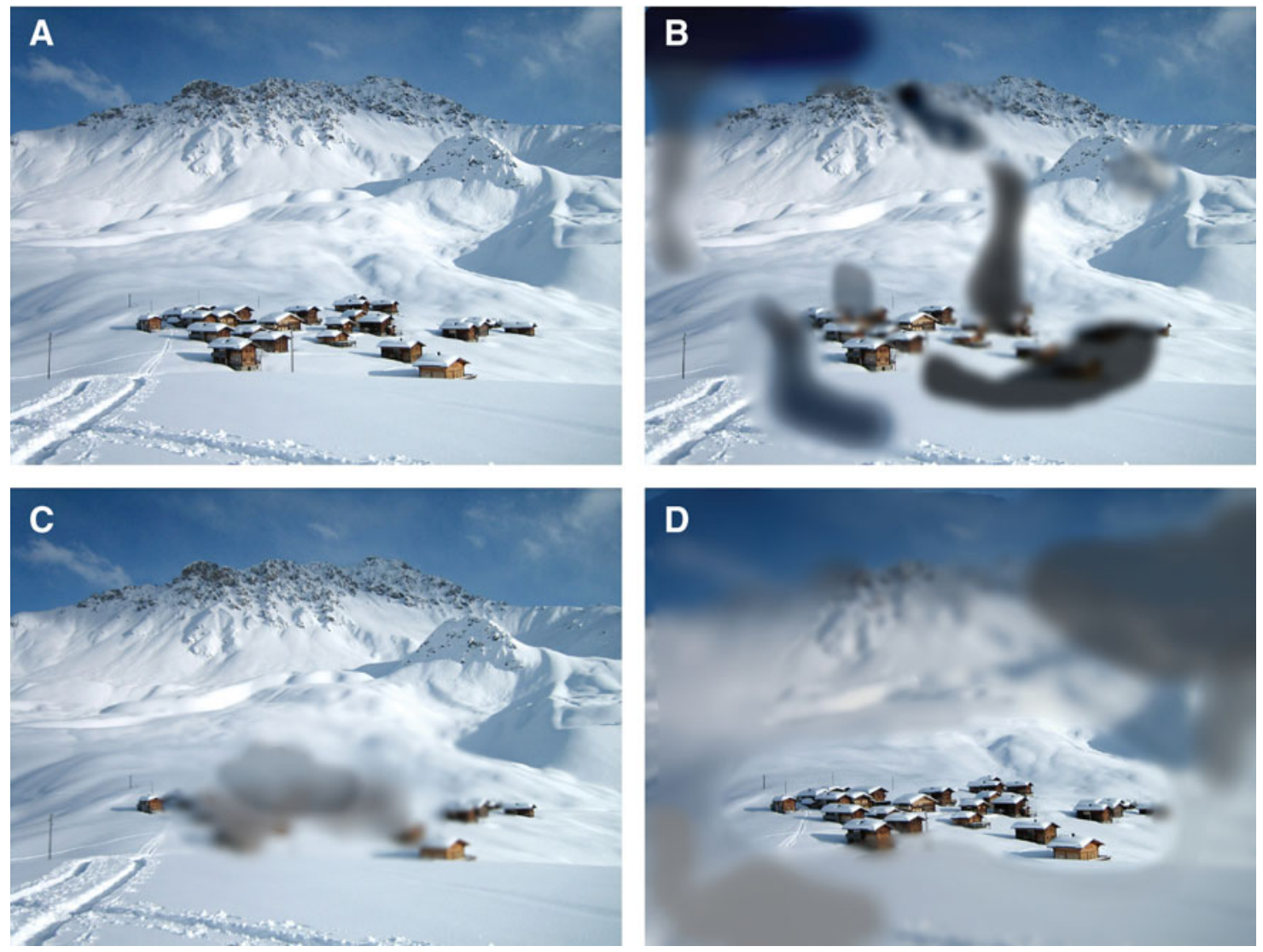

FIG. 1. The mountain village Medergen (Switzerland, 2000 meters above sea level) as seen by a person with normal eyesight (A), and by patients affected by diabetic retinopathy (B), age-related macular degeneration (C), or glaucoma (D).

the normal retina has an intrinsically protective system that has the capacity to cope with and adapt to transient changes in oxygen levels. However, this system may not be sufficient to protect retinal integrity and function in all situations. Especially if hypoxia lasts for an extended period of time, or if hypoxia occurs in the presence of additional stress factors such as certain gene mutations and pre-existing systemic or ocular disease, changing oxygen levels may be devastating for the retina and thus for visual function in human patients. It is clear, for example, that reduced tissue oxygenation negatively influences retinopathy of prematurity (ROP), diabetic retinopathy (DR), age-related macular degeneration (AMD), and glaucoma.

\section{Retinopathy of prematurity}

Changes in retinal oxygenation in preterm infants are associated with ROP, which accounts for $6 \%$ to $18 \%$ of visual impairment in children (Gilbert et al., 1997). After birth, newborns experience oxygen levels that are hyperoxic relative to the in utero situation (Mintz-Hittner and Best, 2009). The retinas of children born at term tolerate this sudden change in oxygenation since the retinal vasculature is already fully developed. In infants born prematurely, however, the relative hyperoxic environment may reduce production of hypoxiarelated pro-angiogenic factors and prevent complete maturation of the retinal vasculature, or even cause vessel dropout. Relative tissue hypoxia, which may follow this hyperoxic phase as soon as retinal cells start to function, is thought to be then responsible for abnormal vessel growth leading to neo- vascularization, and eventually to scarring, formation of hemorrhages, and/or retinal detachment (Mintz-Hittner and Best, 2009). The molecular response to this second phase of ROP centers around activation of hypoxia-inducible transcription factors (HIFs), which regulate expression of various genes important for vessel growth such as vascular endothelial growth factor (VEGF), erythropoietin (EPO), and others (Lee et al., 2004). Although local anti-VEGF therapy may significantly improve disease outcome, future approaches to further increase efficacy of treatment may need to target additional pro- or inhibitory angiogenic factors (Table 1), or upstream mechanisms regulating expression of these factors. Controlled destabilization of HIFA subunits, for example, might be a possible way to simultaneously influence expression of most genes regulating neovascular vessel growth, and may thus have a larger inhibitory impact on disease progression.

Nevertheless, until today the mainstay of ROP treatment remains laser therapy, while the off-label use of anti-VEGF antibodies has only been shown to be superior compared to laser treatment in ROP zone I. Advantages of anti-VEGF antibodies include the potential induction of neovascular regression, as well as the development of a more physiological vasculature (Mintz-Hittner and Kuffel, 2008; Stahl et al., 2011).

\section{Diabetic retinopathy}

DR affects a large percentage of patients suffering from diabetes mellitus. Symptoms include blurred vision, shadows 
Table 1. Selected Key Angiogenic Factors and Inhibitors in the Retina

\begin{tabular}{llll}
\hline Factor & \multicolumn{1}{c}{ Name } & \multicolumn{1}{c}{ Activity } & \multicolumn{1}{c}{ Reference } \\
\hline VEGF & vascular endothelial growth factor & pro-angiogenic & (Witmer et al., 2003) \\
EPO & erythropoietin & (Watanabe et al., 2005) \\
insulin-like growth factor 1 & pro-angiogenic & (Simo et al., 2006) \\
IGF1 & placental growth factor & pro-angiogenic & (Carmeliet et al., 2001) \\
PGF & platelet derived growth factor & pro-angiogenic & (Simo et al., 2006) \\
PDGF & stromal-cell derived factor & pro-angiogenic & (Lima e Silva et al., 2007) \\
SDF & hepatocyte growth factor & pro-angiogenic & (Colombo et al., 2007) \\
HGF & angiopoietin 2 & pro-angiogenic & (Wong et al., 2001) \\
ANG2 & basic fibroblast growth factor & pro-angiogenic & (Kuiper et al., 2004) \\
bFGF & conecting tissue growth factor & pro-angiogenic & (Spranger et al., 1999) \\
CTGF & transforming growth factor & pro-angiogenic & (Lara-Castillo et al., 2009) \\
TGF & atrial natrium peptide & inhibitory & (Spranger et al., 2000) \\
ANP & angiostatin & inhibitory & (Noma et al., 2002) \\
Angiostatin & endostatin & inhibitory & (Sargiannidou et al., 2001) \\
Endostatin & thrombospondin & & \\
TSP-1 & & &
\end{tabular}

and/or missing areas of vision (Fig. 1B), retinal detachments, vitreous hemorrhages, and more. Diabetic retinopathy is a micro-angiopathy and among the most frequent causes for severe visual impairment in industrialized nations (Ferris et al., 1999; Kocur and Resnikoff, 2002). The initial phase of DR is characterized by microvascular occlusion initiated by hyperglycemia. This results in capillary nonperfusion, followed by retinal hypoxia, which leads to arteriovenous shunts characterized by vessel dropout and later by neovascularization. Clinical lesions often found in background diabetic retinopathy include micro-aneurysms with leakage or occlusion, retinal hemorrhages, macular edema, and hard exudates. The primary feature of the proliferative phase of the disease is neovascularization caused by extensive retinal hypoxia, with neovascularization being the result of an interaction between various pro-angiogenic factors with angiogenic inhibitors (Table 1) (Frank, 2004; Antonetti et al., 2012). It is important to note that stimulation or inhibition by these factors largely depends on the disease state. However, since VEGF plays a key role in disease development, novel anti-VEGF therapeutic strategies are now able to fulfill the previously unmet medical need for a treatment, which is superior to traditional laser photocoagulation for diabetic macular edema, for example (Bandello et al., 2012).

Although not fully elucidated, alterations in retinal hemodynamics with reduced blood flow in the retina may be an important factor in addition to hyperglycemia for the initiation of DR. Local or global changes in retinal oxygenation may cause the development of hypoxic areas as the disease progresses (Arden and Sivaprasad, 2011). As in ROP, activation of HIF transcription factors may then be responsible for the production of angiogenic proteins and thus for the development of a neovascular response.

\section{Age-related macular degeneration}

AMD is characterized by distorted, blurred, and reduced central vision (Fig. 1C). Affected individuals have difficulties reading, watching television, and recognizing people's faces. AMD is the leading cause of visual impairment and blindness in elderlies in the developed world (Gehrs et al., 2006). In general, AMD can be of the dry or of the wet form. In the dry form, also called geographic atrophy, retinal pigment epithelial (RPE) cells and photoreceptors in the central retina covering the macula degenerate, leading to loss of central high acuity vision. The wet form, which may or may not follow the dry form, is characterized by neovascularization of the retina with vessels originating from the choroid penetrating the RPE and growing into the neuronal retina. As in DR, alterations in ocular blood flow and hemodynamics, as well as reduced perfusion of the choriocapillaries, have been described. In addition, thickening of Bruch's membrane, alterations of RPE cells with the accumulation of lipofuscin, and the formation of drusen may reduce diffusion of oxygen from the choroid to the retina (Schlingemann, 2004; Terman and Brunk, 2004). This may lead to reduced oxygen tension causing the activation of a hypoxic response, which may lead to the development of neovascular complications. In this response, HIF factors may again be the driving force controlling initiation and progression of the devastating vessel growth (Inoue et al., 2007; Sheridan et al., 2009). The main pro-angiogenic factor in wet AMD seems to be VEGF. Anti-VEGF therapies successfully slow or even prevent neovascularization in AMD patients. Targeting HIF1 prevented production of VEGF in RPE cells in vitro and reduced neovascular vessel growth in animal models in vivo (Zhang et al., 2007, 2010; Yoshida et al., 2010), suggesting that hypoxia-induced HIF1 might be responsible for the development of wet AMD and loss of vision.

\section{Glaucoma}

Glaucoma is the second leading cause of blindness worldwide (Quigley and Broman, 2006). The death of retinal ganglion cells in glaucoma may disconnect the retina from the visual cortex, preventing signal transmission and formation of useful vision in patients. Patients may initially experience blurred and cloudy vision, especially in the periphery (Fig. 1D). If untreated, glaucoma may lead to complete blindness. Vascular abnormalities and altered blood flow at the optic nerve head may lead to local hypoxia, accelerating neuronal cell death in patients (Osborne et al., 2001; Flammer et al., 2002). Again, HIF1 is thought to be involved in the pathology of glaucoma: increased presence of HIF1A was found in glaucomatous eyes and localization of this protein correlated with regions of visual field defects (Tezel and Wax, 2004). 


\section{Hypoxia in Retinal Development: The Good Side of the Coin}

Cells of the retina may experience a period of relative hypoxia before the capillary network in the vascular plexi is established and functional. This has mostly been investigated in mice and rats in which final retinal and vascular development occurs postnatally. At birth, the mouse retina is avascular and three vascular plexi develop from the optic nerve head in a radial fashion within the first 2 weeks of life. Local hypoxia may control production of VEGF, which is essential for the primary vascular plexus in the nerve fiber layer to develop. VEGF is thought to be primarily produced by astrocytes (West et al., 2005), but ganglion cells (Sapieha et al., 2008) may also contribute to the formation of a VEGF gradient with highest concentrations in the initially avascular peripheral retina (Stone et al., 1995). Although VEGF may be most important for development of the primary vascular plexus, factors such as insulin-growth factor 1, placental growth factor, leukemia inhibitory factor, and others play a role as well (Caprara and Grimm, 2012). Similar to the formation of the primary plexus, hypoxia-driven expression of VEGF seems crucial for angiogenic sprouting preceding formation of the deeper plexi. For this step of vascular development, VEGF is expressed by cells of the inner nuclear layer, presumably by Muller glia cells (Stone et al., 1995). Developmental hypoxia and VEGF expression has also been described for the primate retina (Sandercoe et al., 2003), suggesting that the mechanisms governing retinal vascular development might be well conserved.

Since expression of VEGF is mainly controlled by HIF transcription factors, HIFs might be strongly involved in the regulation of the vasculature in the retina. Furthermore, it has been suggested that developmental hypoxia may also participate in controlling the number of retinal neurons through regulating the physiological process of developmental apoptosis or programmed cell death (Maslim et al., 1997; Mervin and Stone, 2002). Thus, it seems important that oxygen levels are kept within a physiological range to ensure proper spatial and timely activation of HIFs and their downstream target genes, especially during development of the retina. Disturbing this fine-tuned system may profoundly influence retinal architecture and thus the functional performance of the tissue with strong consequences for vision. It may therefore not be surprising that mice with a conditional knockout of Hifla in most cells of the peripheral retina do not develop a normal retinal vasculature. In the absence of HIF1A protein, the intermediate vascular plexus does not form, whereas the primary and the deep plexi are less affected. The architecture and cellular composition of the neuronal retina, however, seems normal. Interestingly, lack of HIF1A leads to an increased expression and activation of HIF2A, probably as a compensatory reaction. As a consequence, Epo levels are strongly elevated in these mice (Caprara et al., 2011).

Not only a reduced (lack of HIF1A), but also an overstimulated hypoxic response disturbs retinal development. Von Hippel Lindau (VHL) protein is a main factor in the degradation of HIFA proteins in normoxic conditions. Lack of VHL leads to the stabilization and functional activation of HIF1 and HIF2, even at normal oxygen levels (Haase et al., 2001). Deletion of $V h l$ in the developing retina generates a sustained and misregulated hypoxia-like molecular response with the activation of HIF1 and HIF2. This leads to severe consequences for the retinal vasculature and the neuronal tissue. The embryonic vasculature in the vitreous does not regress and the retinal vasculature does not develop correctly (Kurihara et al., 2010; Lange et al., 2011a). Vascular plexi are severely disturbed and vessels penetrate all cell layers, including the photoreceptor layer. Mis-regulated angiogenic factors include Vegf, Epo, and others. Since exogenous application of a VEGF receptor (FLT1) that binds and inactivates VEGF prevents most of these changes, mis-expression of HIF-controlled VEGF seems responsible for the observed alterations. This is further supported by the rescue of the phenotype by HIF1 ablation (Kurihara et al., 2010). The vascular abnormalities also induce severe retinal degeneration with loss of most neurons, leading to a strong reduction in retinal function and thus in vision (Lange et al., 2011a).

In conclusion, physiological hypoxia is required for proper development of the retinal vasculature and tissue architecture. Only if the hypoxic response system can react properly to changes in tissue oxygenation, the retina will develop into a mature, well-structured, and functional organ. Thus, physiological hypoxia is a critical environmental clue and is essential for the formation of a functional visual system. That it is this hypoxic clue and not only an intrinsically activated genetic program that regulates development of the vasculature is established with experiments involving exposure of newborn mice to hyperoxia to prevent formation of physiological tissue hypoxia. This treatment prevents activation of HIF transcription factors, demonstrating that their normal developmental activation is not due to a developmental program initiated at specified time points after birth, but rather to alterations in tissue oxygenation. Hyperoxia not only prevents HIF activation but also arrests the formation of retinal blood vessels and even leads to vessel dropout in wild type mice. Reactivation of the HIF system after reduction of oxygen levels leads to neovascular changes and loss of neuronal cells (Smith et al., 1994). Such experiments clearly demonstrate that hypoxia provides important environmental signaling cues that are vital for retinal physiology and function.

\section{Hypoxia in Retinal Neuroprotection: Another Good Side of the Coin}

Although long-lasting hypoxia is devastating and may lead to retinal degeneration and loss of vision (see above), shortterm hypoxic exposure can precondition the tissue and prepare it to cope with a subsequent toxic insult. Cells and animals can be preconditioned by a temporary reduction of oxygen concentrations in the cell culture medium or breathing air, respectively. It has been shown that preconditioning of mice protects the retina against ischemic-reperfusion injury (Roth et al., 1998), and against degeneration of photoreceptors after exposure to bright light (Grimm et al., 2002). The underlying molecular mechanisms are unclear but locally produced EPO may be part of the protection. Recombinant EPO delivered by local or systemic injections, or by viral-mediated gene transfer can provide partial protection for photoreceptors in some but not all situations (Grimm et al., 2002, 2004; Rex et al., 2004, 2009). This may suggest that neuroprotective factors in addition to EPO are produced during or after the period of hypoxic preconditioning. The identification of those factors might provide the basis for an efficient therapeutic approach to treat human patients suffering from retinal degeneration. Due to the short-lived effect of hypoxic pre- 
conditioning, it is not possible to test whether the treatment would also protect against slower degenerations induced by gene mutations. It is also not clear whether the combination of factors induced by hypoxic preconditioning would be capable to protect cells in all situations. Erythropoietin alone at least is not. Constitutive overexpression of Epo provides some protection against light damage but not against degeneration induced by a mutation in rod opsin or a mutation in rod phosophdiesterase (Grimm et al., 2004). Direct application of EPO or systemic expression of Epo from a virally transferred gene, however, protects photoreceptors in the presence of a mutation in the peripherin gene (Rex et al., 2009; Sullivan et al., 2011).

Analysis of the retinal transcriptome showed that hypoxic preconditioning differentially regulates a large number of genes, but factors responsible for protection have not yet been defined (Thiersch et al., 2008). It seems clear, however, that expression of HIF1-regulated genes in photoreceptors is not essential for autocrine protection (Thiersch et al., 2009), suggesting either that protective factors are produced by other classes of retinal cells to act in trans on photoreceptors, or that factors controlled by HIF2 (or by other transcription factors differentially regulated by hypoxia) are needed by photoreceptors to survive light exposure. Possibly, full protection is only achieved if both autocrine and paracrine factors are acting together. Deletion of VHL from rod photoreceptor cells induces a hypoxia-like response in normoxia with the activation of HIF1, HIF2, and STAT3, and protects photoreceptors from light damage. However, protection is only transient (Lange et al., 2011b), again arguing that a hypoxic response restricted to photoreceptors participates in the protection but is not sufficient for full protection.

The response to reduced oxygen tension may not be solely determined by the stabilization of HIF transcription factors. Increasing evidence suggests that epigenetic mechanisms may also be involved in the regulation of HIF-mediated gene transcription. Retinas tolerating ischemia contained increased levels of trimethylated histone $\mathrm{H} 3$ and mono-ubiquitinated histone H2A (Stowell et al., 2010), both of which are implicated in epigenetic transcriptional regulation (Bantignies and Cavalli, 2006). In addition, DNase-1 hypersensitive areas obviously allow facilitated binding of HIF transcription factors to their respective binding sites in promoters of target genes (Schodel et al., 2011), suggesting that epigenetic mechanisms are important regulators of the hypoxic response in a variety of situations.

\section{Conclusions and Outlook}

The retina is one of the most metabolically active tissues of the body. Photoreceptor cells consume up to $10^{8}$ ATP molecules per second in darkness (Okawa et al., 2008), and cells of the RPE are among the most active phagocytes of the body (Reme, 2000). Thus, proper function of the adult retina requires that cells are sufficiently supplied with nutrients and oxygen. Any alterations in oxygenation levels may have devastating consequences for vision if no adequate cellular or tissue response can be activated to cope with the condition. Understanding how such a response is regulated on a molecular level may not only increase our knowledge about fundamental biological processes during development, maturation, and aging, but may also reveal new targets for the treatment of sight-frightening diseases in human patients.
Factors in the HIF-activation pathway, HIF target genes and/ or proteins regulating tissue oxygenation itself may provide a number of possibilities to support retinal cells and to maintain normal retinal physiology and function.

\section{Author Disclosure Statement}

No competing financial interests exist.

Supported by a grant of the Swiss National Science Foundation (SNF).

\section{References}

Antonetti DA, Klein R, and Gardner TW. (2012). Diabetic retinopathy. N Engl J Med 366:1227-1239.

Arden GB and Sivaprasad S. (2011). Hypoxia and oxidative stress in the causation of diabetic retinopathy. Curr Diabetes Rev 7:291-304.

Bandello F, Cunha-Vaz J, Chong NV, Lang GE, Massin P, Mitchell P, Porta M, Prunte C, Schlingemann R, and SchmidtErfurth U. (2012). New approaches for the treatment of diabetic macular oedema: Recommendations by an expert panel. Eye (Lond) 26:485-493.

Bantignies F and Cavalli G. (2006). Cellular memory and dynamic regulation of polycomb group proteins. Curr Opin Cell Biol 18:275-283.

Barthelmes D, Bosch MM, Merz TM, Petrig BL, Truffer F, Bloch KE, Holmes TA, Cattin P, Hefti U, Sellner M, Sutter FK, Maggiorini M, and Landau K. (2011). Delayed appearance of high altitude retinal hemorrhages. PLoS One. 6:e11532.

Bosch MM, Barthelmes D, Merz TM, Bloch KE, Turk AJ, Hefti U, Sutter FK, Maggiorini M, Wirth MG, Schoch OD, and Landau K. (2008). High incidence of optic disc swelling at very high altitudes. Arch Ophthalmol 126:644-650.

Bosch MM, Merz TM, Barthelmes D, Petrig BL, Truffer F, Bloch KE, Turk A, Maggiorini M, Hess T, Schoch OD, Hefti U, Sutter FK, Pichler J, Huber A, and Landau K. (2009). New insights into ocular blood flow at very high altitudes. J Appl Physiol 106:454-460.

Caprara C and Grimm C. (2012). From oxygen to erythropoietin: Relevance of hypoxia for retinal development, health and disease. Prog Retin Eye Res 31:89-119.

Caprara C, Thiersch M, Lange C, Joly S, Samardzija M, and Grimm C. (2011). HIF1A is essential for the development of the intermediate plexus of the retinal vasculature. Invest Ophthalmol Vis Sci 52: 2109-2117.

Carmeliet P, Moons L, Luttun A, Vincenti V, Compernolle V, De Mol M, Wu Y, Bono F, Devy L, Beck H, Scholz D, Acker T, DiPalma T, Dewerchin M, Noel A, Stalmans I, Barra A, Blacher S, Vandendriessche T, Ponten A, Eriksson U, Plate $\mathrm{KH}$, Foidart JM, Schaper W, Charnock-Jones DS, Hicklin DJ, Herbert JM, Collen D, and Persico MG. (2001). Synergism between vascular endothelial growth factor and placental growth factor contributes to angiogenesis and plasma extravasation in pathological conditions. Nat Med 7:575-583.

Colombo ES, Menicucci G, McGuire PG, and Das A. (2007). Hepatocyte growth factor/scatter factor promotes retinal angiogenesis through increased urokinase expression. Invest Ophthalmol Vis Sci 48:1793-1800.

Ferris FL, 3rd, Davis MD, and Aiello LM. (1999). Treatment of diabetic retinopathy. N Engl J Med 341:667-678.

Fischer MD, Willmann G, Schatz A, Schommer K, Zhour A, Zrenner E, Bartz-Schmidt KU, and Gekeler F. (2012). Structural and functional changes of the human macula during acute exposure to high altitude. PLoS One 7:e36155.

Flammer J, Orgul S, Costa VP, Orzalesi N, Krieglstein GK, Serra LM, Renard JP, and Stefansson E. (2002). The impact of ocular blood flow in glaucoma. Prog Retin Eye Res 21:359-393. 
Frank RN. (2004). Diabetic retinopathy. N Engl J Med 350:48-58. Frayser R, Houston CS, Bryan AC, Rennie ID, and Gray G. (1970). Retinal hemorrhage at high altitude. N Engl J Med 282:1183-1184.

Gehrs KM, Anderson DH, Johnson LV, and Hageman GS. (2006). Age-related macular degeneration: Emerging pathogenetic and therapeutic concepts. Ann Med 38:450-471.

Gilbert C, Rahi J, Eckstein M, O'Sullivan J, and Foster A. (1997). Retinopathy of prematurity in middle-income countries. Lancet 350:12-14.

Grimm C, Wenzel A, Groszer M, Mayser H, Seeliger M, Samardzija M, Bauer C, Gassmann M, and Reme CE. (2002) HIF-1-induced erythropoietin in the hypoxic retina protects against light-induced retinal degeneration. Nat Med 8:718724.

Grimm C, Wenzel A, Stanescu D, Samardzija M, Hotop S, Groszer M, Naash M, Gassmann M, and Reme C. (2004) Constitutive overexpression of human erythropoietin protects the mouse retina against induced but not inherited retinal degeneration. J Neurosci 24:5651-5658.

Haase VH, Glickman JN, Socolovsky M, and Jaenisch R. (2001). Vascular tumors in livers with targeted inactivation of the von Hippel-Lindau tumor suppressor. Proc Natl Acad Sci USA 98:583-1588.

Hackett SF, Wiegand S, Yancopoulos G, and Campochiaro PA. (2002). Angiopoietin-2 plays an important role in retinal angiogenesis. J Cell Physiol 192:182-187.

Ho TY, Kao WF, Lee SM, Lin PK, Chen JJ, and Liu JH. (2011). High-altitude retinopathy after climbing Mount Aconcagua in a group of experienced climbers. Retina 31:1650-1655.

Inoue $\mathrm{Y}$, Yanagi $\mathrm{Y}$, Matsuura $\mathrm{K}$, Takahashi $\mathrm{H}$, Tamaki $\mathrm{Y}$, and Araie M. (2007). Expression of hypoxia-inducible factor 1alpha and 2alpha in choroidal neovascular membranes associated with age-related macular degeneration. $\mathrm{Br} \mathrm{J}$ Ophthalmol 91:1720-1721.

Kocur I and Resnikoff S. (2002). Visual impairment and blindness in Europe and their prevention. Br J Ophthalmol 86:716722.

Kuiper EJ, Witmer AN, Klaassen I, Oliver N, Goldschmeding R, and Schlingemann RO. (2004). Differential expression of connective tissue growth factor in microglia and pericytes in the human diabetic retina. Br J Ophthalmol 88:1082-1087.

Kurihara T, Kubota Y, Ozawa Y, Takubo K, Noda K, Simon MC, Johnson RS, Suematsu M, Tsubota K, Ishida S, Goda N, Suda T, and Okano H. (2010). von Hippel-Lindau protein regulates transition from the fetal to the adult circulatory system in retina. Development 137:1563-1571.

Lange C, Caprara C, Tanimoto N, Beck S, Huber G, Samardzija M, Seeliger M, and Grimm C. (2011a). Retina-specific activation of a sustained hypoxia-like response leads to severe retinal degeneration and loss of vision. Neurobiol Dis 41:119130.

Lange C, Heynen SR, Tanimoto N, Thiersch M, Le YZ, Meneau I, Seeliger MW, Samardzija M, Caprara C, and Grimm C. (2011b). Normoxic activation of hypoxia-inducible factors in photoreceptors provides transient protection against lightinduced retinal degeneration. Invest Ophthalmol Vis Sci 52:5872-5880.

Lara-Castillo N, Zandi S, Nakao S, Ito Y, Noda K, She H, Ahmed M, Frimmel S, Ablonczy Z, and Hafezi-Moghadam A. (2009). Atrial natriuretic peptide reduces vascular leakage and choroidal neovascularization. Am J Pathol 175:2343-2350.

Lee JW, Bae SH, Jeong JW, Kim SH, and Kim KW. (2004). Hypoxia-inducible factor (HIF-1)alpha: Its protein stability and biological functions. Exp Mol Med 36:1-12.
Lima e Silva R, Shen J, Hackett SF, Kachi S, Akiyama H, Kiuchi K, Yokoi K, Hatara MC, Lauer T, Aslam S, Gong YY, Xiao WH, Khu NH, Thut C, and Campochiaro PA. (2007). The SDF$1 /$ CXCR4 ligand/receptor pair is an important contributor to several types of ocular neovascularization. FASEB J 21:32193230.

Maslim J, Valter K, Egensperger R, Hollander H, and Stone J. (1997). Tissue oxygen during a critical developmental period controls the death and survival of photoreceptors. Invest Ophthalmol Vis Sci 38:1667-1677.

McNulty R, Wang H, Mathias RT, Ortwerth BJ, Truscott RJ, and Bassnett S. (2004). Regulation of tissue oxygen levels in the mammalian lens. J Physiol 559:883-898.

Mervin K and Stone J. (2002). Regulation by oxygen of photoreceptor death in the developing and adult C57BL/6J mouse. Exp Eye Res. 75:715-722.

Mintz-Hittner HA and Kuffel RR, Jr. (2008). Intravitreal injection of bevacizumab (avastin) for treatment of stage 3 retinopathy of prematurity in zone I or posterior zone II. Retina 28:831838.

Mintz-Hittner HA and Best LM. (2009). Antivascular endothelial growth factor for retinopathy of prematurity. Curr Opin Pediatr 21:182-187.

Morris DS, Severn PS, Smith J, Somner JE, Stannard KP, and Cottrell DG. (2007). High altitude and retinal detachment. High Alt Med Biol 8:337-339.

Noma H, Funatsu H, Yamashita H, Kitano S, Mishima HK, and Hori S. (2002). Regulation of angiogenesis in diabetic retinopathy: Possible balance between vascular endothelial growth factor and endostatin. Arch Ophthalmol 120:10751080.

Okawa H, Sampath AP, Laughlin SB, and Fain GL. (2008). ATP consumption by mammalian rod photoreceptors in darkness and in light. Curr Biol 18:1917-1921.

Osborne NN, Melena J, Chidlow G, and Wood JP. (2001). A hypothesis to explain ganglion cell death caused by vascular insults at the optic nerve head: Possible implication for the treatment of glaucoma. Br J Ophthalmol 85:1252-1259.

Pavlidis M, Stupp T, Georgalas I, Georgiadou E, Moschos M, and Thanos S. (2005). Multifocal electroretinography changes in the macula at high altitude: A report of three cases. Ophthalmologica 219:404-412.

Quigley HA and Broman AT. (2006). The number of people with glaucoma worldwide in 2010 and 2020. Br J Ophthalmol 90:262-267.

Reme CE. (2000). [Photoreceptor renewal and the pigment epithelium of the retina-Congratulations to a pioneer in retinal research: Richard W. Young]. Klin Monbl Augenheilkd 216:129-132.

Rex TS, Allocca M, Domenici L, Surace EM, Maguire AM, Lyubarsky A, Cellerino A, Bennett J, and Auricchio A. (2004). Systemic but not intraocular Epo gene transfer protects the retina from light-and genetic-induced degeneration. Mol Ther 10:855-861.

Rex TS, Wong Y, Kodali K, and Merry S. (2009). Neuroprotection of photoreceptors by direct delivery of erythropoietin to the retina of the retinal degeneration slow mouse. Exp Eye Res 89:735-740.

Roth S, Li B, Rosenbaum PS, Gupta H, Goldstein IM, Maxwell KM, and Gidday JM. (1998). Preconditioning provides complete protection against retinal ischemic injury in rats. Invest Ophthalmol Vis Sci 39:777-785.

Safvati A, Cole N, Hume E, and Willcox M. (2009). Mediators of neovascularization and the hypoxic cornea. Curr Eye Res 34:501-514 
Sandercoe TM, Geller SF, Hendrickson AE, Stone J, and Provis JM. (2003). VEGF expression by ganglion cells in central retina before formation of the foveal depression in monkey retina: Evidence of developmental hypoxia. J Comp Neurol 462: 42-54.

Sapieha P, Sirinyan M, Hamel D, Zaniolo K, Joyal JS, Cho JH, Honore JC, Kermorvant-Duchemin E, Varma DR, Tremblay S, Leduc M, Rihakova L, Hardy P, Klein WH, Mu X, Mamer O, Lachapelle P, Di Polo A, Beausejour C, Andelfinger G, Mitchell G, Sennlaub F, and Chemtob S. (2008). The succinate receptor GPR91 in neurons has a major role in retinal angiogenesis. Nat Med 14:1067-1076.

Sargiannidou I, Zhou J, and Tuszynski GP. (2001). The role of thrombospondin-1 in tumor progression. Exp Biol Med (Maywood) 226:726-733.

Schlingemann RO. (2004). Role of growth factors and the wound healing response in age-related macular degeneration. Graefes Arch Clin Exp Ophthalmol 242:91-101.

Schodel J, Oikonomopoulos S, Ragoussis J, Pugh CW, Ratcliffe PJ, and Mole DR. (2011). High-resolution genome-wide mapping of HIF-binding sites by ChIP-seq. Blood 117:e207-217.

Sheridan CM, Pate S, Hiscott P, Wong D, Pattwell DM, and Kent D. (2009). Expression of hypoxia-inducible factor-1alpha and -2alpha in human choroidal neovascular membranes. Graefes Arch Clin Exp Ophthalmol 247:1361-1367.

Simo R, Carrasco E, Garcia-Ramirez M, and Hernandez C. (2006). Angiogenic and antiangiogenic factors in proliferative diabetic retinopathy. Curr Diabetes Rev 2:71-98.

Smith LE, Wesolowski E, McLellan A, Kostyk SK, D'Amato R, Sullivan R, and D'Amore PA. (1994). Oxygen-induced retinopathy in the mouse. Invest Ophthalmol Vis Sci 35:101-111.

Spranger J, Hammes HP, Preissner KT, Schatz H, and Pfeiffer AF. (2000). Release of the angiogenesis inhibitor angiostatin in patients with proliferative diabetic retinopathy: Association with retinal photocoagulation. Diabetologia 43:1404-1407.

Spranger J, Meyer-Schwickerath R, Klein M, Schatz H, and Pfeiffer A. (1999). Deficient activation and different expression of transforming growth factor-beta isoforms in active proliferative diabetic retinopathy and neovascular eye disease. Exp Clin Endocrinol Diabetes 107:21-28.

Stahl A, Agostini H, Jandeck C, and Lagreze W. (2011). [Pharmacological treatment for retinopathy of prematurity]. Ophthalmologe 108:777-785.

Stone J, Itin A, Alon T, Pe'er J, Gnessin H, Chan-Ling T, and Keshet E. (1995). Development of retinal vasculature is mediated by hypoxia-induced vascular endothelial growth factor (VEGF) expression by neuroglia. J Neurosci 15:4738-4747.

Stowell C, Wang L, Arbogast B, Lan JQ, Cioffi GA, Burgoyne CF, and Zhou A. (2010). Retinal proteomic changes under different ischemic conditions. Implication of an epigenetic regulatory mechanism. Int J Physiol Pathophysiol Pharmacol 2:148-160.

Sullivan T, Kodali K, Rex TS. (2011). Systemic gene delivery protects the photoreceptors in the retinal degeneration slow mouse. Neurochem Res 36:613-618.

Terman A and Brunk UT. (2004). Lipofuscin. Int J Biochem Cell Biol 36:1400-1404.

Tezel G and Wax MB. (2004). Hypoxia-inducible factor 1alpha in the glaucomatous retina and optic nerve head. Arch Ophthalmol 122:1348-1356.

Thiersch M, Lange C, Joly S, Heynen S, Le YZ, Samardzijan, and Grimm C. (2009). Retinal neuroprotection by hypoxic preconditioning is independent of hypoxia-inducible factor- 1 al- pha expression in photoreceptors. Eur J Neurosci 29:22912302.

Thiersch M, Raffelsberger W, Frigg R, Samardzija M, Wenzel A, Poch O, and Grimm C. (2008). Analysis of the retinal gene expression profile after hypoxic preconditioning identifies candidate genes for neuroprotection. BMC Genomics 9:73.

Watanabe D, Suzuma K, Matsui S, Kurimoto M, Kiryu J, Kita M, Suzuma I, Ohashi H, Ojima T, Murakami T, Kobayashi T, Masuda S, Nagao M, Yoshimura N, and Takagi H. (2005). Erythropoietin as a retinal angiogenic factor in proliferative diabetic retinopathy. N Engl J Med 353:782-792.

West H, Richardson WD, and Fruttiger M. (2005). Stabilization of the retinal vascular network by reciprocal feedback between blood vessels and astrocytes. Development 132:18551862.

Wiedman M. (1975). High altitude retinal hemorrhage. Arch Ophthalmol 93:401-403.

Willmann G, Fischer MD, Schatz A, Schommer K, Messias A, Zrenner E, Bartz-Schmidt KU, and Gekeler F. (2011). Quantification of optic disc edema during exposure to high altitude shows no correlation to acute mountain sickness. PLoS One 6:e27022.

Willmann G, Ivanov IV, Fischer MD, Lahiri S, Pokharel RK, Werner A, and Khurana TS. (2010). Effects on colour discrimination during long term exposure to high altitudes on $\mathrm{Mt}$ Everest. Br J Ophthalmol 94:1393-1397.

Witmer AN, Vrensen GF, Van Noorden CJ, and Schlingemann RO. (2003). Vascular endothelial growth factors and angiogenesis in eye disease. Prog Retin Eye Res 22:1-29.

Wong CG, Rich KA, Liaw LH, Hsu HT, and Berns MW. (2001). Intravitreal VEGF and bFGF produce florid retinal neovascularization and hemorrhage in the rabbit. Curr Eye Res 22: 140-147.

Yoshida T, Zhang H, Iwase T, Shen J, Semenza GL, and Campochiaro PA. (2010). Digoxin inhibits retinal ischemia-induced HIF-1alpha expression and ocular neovascularization. FASEB J 24:1759-1767.

Zhang C, Wang YS, Wu H, Zhang ZX, Cai Y, Hou HY, Zhao W, Yang XM, and Ma JX. (2010). Inhibitory efficacy of hypoxiainducible factor 1alpha short hairpin RNA plasmid DNAloaded poly (D, L-lactide-co-glycolide) nanoparticles on choroidal neovascularization in a laser-induced rat model. Gene Ther 17:338-351.

Zhang $\mathrm{P}$, Wang Y, Hui Y, Hu D, Wang H, Zhou J, and Du $\mathrm{H}$. (2007). Inhibition of VEGF expression by targeting HIF-1 alpha with small interference RNA in human RPE cells. Ophthalmologica 221:411-417.
Address correspondence to: Christian Grimm Lab for Retinal Cell Biology Dept. Ophthalmology, USZ University of Zurich Wagistrasse 14 8952 Schlieren Zurich Switzerland

E-mail: cgrimm@opht.uzh.ch

Received April 8, 2012; accepted in final form May 26, 2012. 